\title{
Plasma pharmacokinetics after combined therapy of gemcitabine and oral S-1 for unresectable pancreatic cancer
}

\author{
Bunzo Nakata*, Ryosuke Amano, Shigetomi Nakao, Tatsuro Tamura, Osamu Shinto, Toshiki Hirakawa, \\ Yoshihiro Okita, Nobuya Yamada, Kosei Hirakawa
}

\begin{abstract}
Background: The combination of gemcitabine (GEM) and S-1, an oral 5-fluorouracil (5-FU) derivative, has been shown to be a promising regimen for patients with unresectable pancreatic cancer.

Methods: Six patients with advanced pancreatic cancer were enrolled in this pharmacokinetics (PK) study. These patients were treated by oral administration of S-1 $30 \mathrm{mg} / \mathrm{m}^{2}$ twice daily for 28 consecutive days, followed by a 14-day rest period and intravenous administration of GEM $800 \mathrm{mg} / \mathrm{m}^{2}$ on days 1, 15 and 29 of each course. The PK parameters of GEM and/or 5-FU after GEM single-administration, S-1 single-administration, and co-administration of GEM with pre-administration of S-1 at 2-h intervals were analyzed.

Results: The maximum concentration (Cmax), the area under the curve from the drug administration to the infinite time (AUCinf), and the elimination half-life (T1/2) of GEM were not significantly different between GEM administration with and without S-1. The Cmax, AUCinf, T1/2, and the time required to reach Cmax (Tmax) were not significantly different between S-1 administration with and without GEM.
\end{abstract}

Conclusion: There were no interactions between GEM and S-1 regarding plasma PK of GEM and 5-FU.

\section{Background}

Unresectable pancreatic cancer is known to have a poor prognosis, with most patients dying within several months of diagnosis. However, recent progress in chemotherapy using gemcitabine (GEM) for this disease has improved patient survival. A number of phase III clinical trials have been performed to determine the GEM regimens that lead to the greatest increases in survival compared with GEM monotherapy. To date, only one regimen has been shown to yield significantly longer survival periods than GEM alone in phase III studies: GEM with erlotinib, an epidermal growth factor receptor (EGFR)-targeting agent [1].

S-1 is an oral fluoropyrimidine derivative that contains tegafur (a 5-FU prodrug) and a reversible competitive dihydropyrimidine dehydrogenase (DPD) inhibitor, 5chloro-2,4-dihydrogenase (CDHP). As DPD is a rate-

\footnotetext{
*Correspondence: bunzo@med.osaka-cu.ac.jp
Department of Surgical Oncology, Osaka City University Graduate School of

* Correspondence: bunzo@med.osaka-cu.ac.jp Medicine, Osaka 545-8585, Japan
}

(c) 2010 Nakata et al; licensee BioMed Central Ltd. This is an Open Access article distributed under the terms of the Creative Commons

limiting enzyme that degrades 5-FU, CDHP is expected to enhance the cytotoxicity of 5 -FU by prolonging high 5 -FU concentrations in blood and tumor tissues [2]. In Japan, S-1 has been clinically used as a first-line chemotherapeutic agent for pancreatic cancer since being approved for national health insurance coverage in 2006. A phase II study of S-1 for 40 patients with metastatic pancreatic cancers resulted in the response rate of $37.5 \%$ and the overall survival time of 9.2 months [3].

As the efficacy of S-1 monotherapy against pancreatic cancer is not satisfactory, numerous studies using S-1 combined with GEM have been conducted. Two phase I studies and two phase II studies of the combination therapy showed promising efficacy and acceptable adverse events [4-7]. A phase III study comparing GEM +S-1 vs. S-1 monotherapy vs. GEM monotherapy for metastatic pancreatic cancer (GEST study) has been underway in Japan and Taiwan since 2007. In contrast to the large number of clinical trials regarding GEM+S1 , pharmacokinetic studies to investigate the interaction 
between the two agents have been very limited. This is the first study to compare the plasma pharmacokinetics (PK) of GEM and 5-FU after GEM+S-1 to those after single administration of individual drugs in the same patients.

\section{Methods}

\section{Eligibility}

Patients under 80 years of age with a diagnosis of unresectable pancreatic cancer were eligible. Eastern Cooperative Oncology Group performance status (PS) $\leq 2$, and life expectancy $\geq 12$ weeks were required. Patients were required to have measurable or assessable disease and to have had no chemotherapy or immunotherapy before enrolling. Other eligibility requirements included adequate bone marrow function $(\mathrm{Hb} \geq 9.0 \mathrm{~g} / \mathrm{dl}$, white blood cells between 4,000 and $12,000 / \mu \mathrm{l}$, neutrophils $\geq$ $2,000 / \mu \mathrm{l}$ and platelets $\geq 100,000 / \mu \mathrm{l})$, total bilirubin $\leq 2$ $\mathrm{mg} / \mathrm{dl}$, AST and ALT $\leq 100 \mathrm{IU} / \mathrm{l}$, alkali phosphatase $\leq 2$ times the upper normal level, and BUN and serum creatinine $\leq$ the upper normal level.

\section{Patients}

A total of six patients with unresectable pancreatic cancer diagnosed by imaging studies including abdominal dynamic computed tomography were enrolled in this study between April and June, 2007. Mean age \pm standard deviation was $68 \pm 4$ years (range, 63-73 years). One case had liver metastasis, three had peritoneal metastasis, and two had tumors involving the celiac and/or superior mesenteric arteries. Informed consent from all participants was obtained. The institutional review board for human experimentation in our hospital approved the study protocols.

\section{Treatment}

S-1 (Taiho Pharmaceutical Co., Tokyo, Japan) was administered orally at a dose of $30 \mathrm{mg} / \mathrm{m}^{2}$ twice daily after a meal. One course consisted of consecutive administration for 28 days, followed by a 14-day rest period. GEM $800 \mathrm{mg} / \mathrm{m}^{2}$ in $100 \mathrm{ml}$ normal saline was administered intravenously (i.v.) for $30 \mathrm{~min}$ on days 1, 15 and 29 of each course. The regimen was set by referring to previous clinical trials [4-7].

\section{Sample collection}

Blood samples were drawn on days 1, 3 and 15 of the first course. The object of sampling at day 1 was to monitor the plasma PK of GEM after administration of GEM alone. Subsequently, S-1 administration on day 1 of the first course began at the evening after blood samplings. The object of sampling at day 3 was to monitor the plasma PK of 5-FU after administration of S-1 alone. The object of sampling at day 15 was to examine the changes in individual drug PK after other drug administration. For this purpose, S-1 was administered 2 $\mathrm{h}$ before administration of GEM (Figure 1), when the plasma concentration of 5-FU had increased substantially [8]. Each peripheral blood sample $(2 \mathrm{ml})$ was collected into a heparinized tube that contained $20 \mu \mathrm{l}$ of tetrahydrouridine (a cytidine deaminase competitive inhibitor) solution at a concentration of $10 \mathrm{mg} / \mathrm{ml}$. The samples were centrifuged at $3000 \mathrm{rpm}$ for $10 \mathrm{~min}$. Plasma was stored at $-20^{\circ} \mathrm{C}$ until the measurement of 5FU and GEM concentrations.

\section{GEM assay}

The high-performance liquid chromatography (HPLC) system consisted of a Waters 2690 liquid chromatograph separation module and a Waters SMH column heater (all from Waters (MA, USA). The Atlantis ${ }^{\mathrm{R}} \mathrm{dC} 18$ column $(150 \times 4.6 \mathrm{~mm}$; particle size, $5 \mu \mathrm{m}$; Waters $)$ was used for the peak separation of GEM. The HPLC mobile phase was a solution of $5 \mathrm{mM}$ phosphate buffer $(\mathrm{pH}$ 7.2). The ultraviolet detector was a Waters 2487 (Waters), and was used at $272 \mathrm{~nm}$. Plasma samples were deproteinized with $20 \%$ TCA, and the supernatants were filtered using Ultrafree-MC (Nihon Millipore, Tokyo, Japan) with pore diameters of $0.20 \mu \mathrm{m}$. Aliquots of 20 $\mu \mathrm{l}$ were injected into the HPLC system. The quantitative range of this method was $50-40000 \mathrm{ng} / \mathrm{ml}$.

\section{5-FU assay}

The high-performance liquid chromatographic-mass spectrometry (LC/MS) system consisted of a Micromass ZQ-2000 mass spectrometer, a Waters 2695 liquid chromatograph separation module and a Waters SMH column heater (all from Waters). The Atlantis ${ }^{\mathrm{R}} \mathrm{dC} 18$ column $(150 \times 2.1 \mathrm{~mm}$; particle size, $5 \mu \mathrm{m}$; Waters $)$ was used for the peak separation of 5-FU. The HPLC mobile phase was a solution mixed purified water and acetonitrile. The mass spectrometer was used in the negative ESI mode. The detector was used in SIR mode with a selected ion recording procedure at $\mathrm{m} / \mathrm{z}=128.9$ for 5 FU and at $\mathrm{m} / \mathrm{z}=130.9$ for 5 -FU- ${ }^{15} \mathrm{~N}_{2}$. To plasma samples, internal standard solution (including $5-\mathrm{FU}-{ }^{15} \mathrm{~N}_{2}$ ) was added, and was then extracted with ethyl acetate. The organic layer was evaporated to dryness under a stream of nitrogen. The residue was dissolved in purified water, and after vortex mixing, the mixture was filtered using Ultrafree-MC (Nihon Millipore) with pore diameters of $0.20 \mu \mathrm{m}$. Aliquots of $20 \mu \mathrm{l}$ were injected into the LC/MS system. The quantitative range of this method was $5-500 \mathrm{ng} / \mathrm{ml}$.

\section{Statistical analysis}

The area under the curve from the drug (S-1 or GEM) administration to the infinite time (AUCinf) was 

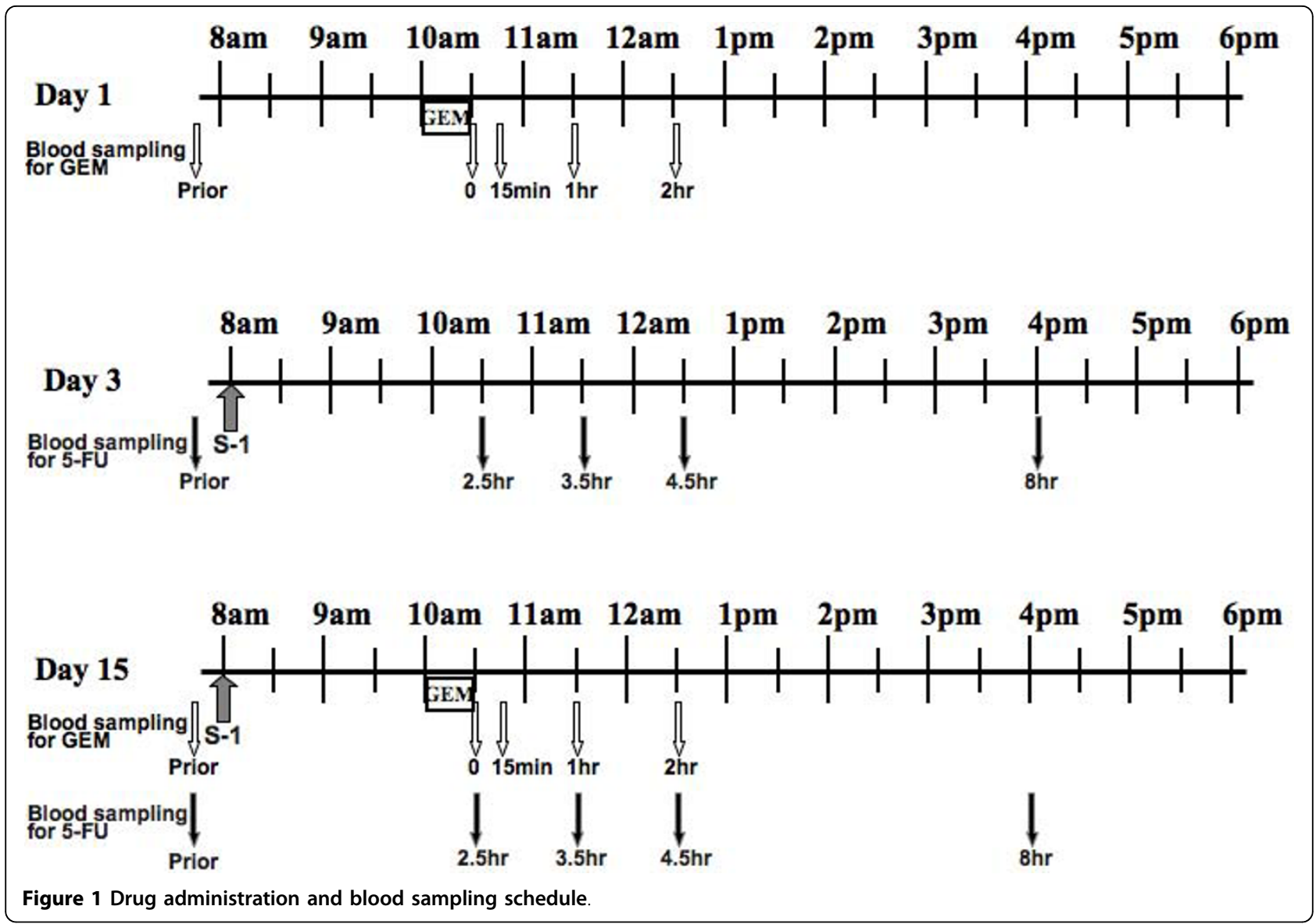

calculated according to the trapezoidal rule using the WinNonlin program (Ver. 5.2; Pharsight Co., Mountain View, CA, USA). Two-sided paired Student's $t$-test on log-transformed plasma concentration data was used to compare the maximum concentration $(\mathrm{Cmax})$ and AUCinf between single administration and co-administration. The two-sided paired Student's $t$-test was conducted on the elimination half-life (T 1/2) and time required to reach $\mathrm{Cmax}(\mathrm{T} \max )$ in order to compare data for single administration and co-administration. A $P$ value of $<0.05$ was considered to be statistically significant.

\section{Results}

\section{Clinical outcome}

Five of six patients were treated by GEM+S-1 for 5 to 16 courses (median, 8 courses). However, it was necessary to reduce the doses of S-1 and/or GEM by approximately $25 \%$ due to grade 3 or more neutropenia for two patients after one course, and for two patients after three courses. The regimen was stopped at the end of one course in one patient who could not continue oral intake of S-1 due to developing the stenosis at Treitz ligament by cancer invasion. The MST of total patients studied was 12.5 months, ranging from 3 to 22 months. The 1-year survival rates were $67 \%$. One partial response was observed. SPan-1, one of reliable tumor marker for pancreatic cancer [9], titers in sera were decreased 50\% or more in all of 5 patients who had abnormal level of SPan-1 prior to the treatment.

\section{Plasma PK}

There were no significant differences between plasma PK parameters of GEM after administration of GEM alone and GEM+S-1 (Table 1, Figure 2). There were no significant differences between the plasma PK parameters of 5-FU after administration of S-1 alone and GEM+S-1 (Table 2, Figure 3).

\section{Discussion}

For the last decade, GEM monotherapy has been the standard chemotherapy regimen to treat advanced pancreatic cancer. The drug has an approximately $5 \%$ response rate and improves MST to less than 6 months [10]. Clinical trial data has demonstrated a response rate of $44-48 \%$ and an MST of 10.1-12.5 months when S-1 is administrated with GEM [6,7]. The efficacy of this combination therapy, including our regimen, thus appears to 
Table 1 Comparison of pharmacokinetic parameters of gemcitabine (GEM) in plasma between administraion of GEM alone and GEM+S1

\begin{tabular}{lccc}
\hline & Cmax (ng/ml) & AUCinf (hXng/ml) & T1/2 (h) \\
\hline Day 1 & $15833 \pm 2477$ & $8467 \pm 1092$ & $0.12 \pm 0.033$ \\
(GEM alone) & & & \\
Day 15 & $14924 \pm 5828$ & $8384 \pm 2915$ & $0.153 \pm 0.069$ \\
(GEM+S-1) & & & \\
P-value & 0.604 & 0.7406 & 0.1594
\end{tabular}

GEM was intravenously given at a dose of $800 \mathrm{mg} / \mathrm{m2}$. S-1 was orally given at a dose of $30 \mathrm{mg} / \mathrm{m} 2$.

Cmax, maximum plasma concentration;

AUCinf, area under plasma concentration-time curve from time zero to infnite time; T1/2, elimination half-life.

Titers are expressed as means $\pm S D(n=6)$. P-values were examined by twosided paired t-test after log-transformation. be better than GEM monotherapy, although a true evaluation requires data from the ongoing phase III trial (GEST study).

Our results demonstrated that pre-administration of S-1 did not increase Cmax, AUCinf or T1/2 of plasma GEM (Table 1, Figure 2). Nakamura et al. performed a PK study of GEM with S-1; S-1 was given orally at a dose of $30 \mathrm{mg} / \mathrm{m}^{2}$ twice daily for 14 consecutive days, followed by a 1 -week rest. GEM $1000 \mathrm{mg} / \mathrm{m}^{2}$ was given in a 30 -min i.v. on day 8 and day 15 . In six patients with metastatic pancreatic cancer, the PK parameters of Cmax and AUCinf for GEM were examined on day 8. It was concluded that their data were similar to those of GEM single-administration, as determined in a phase I study [11] carried out by other investigators [12].

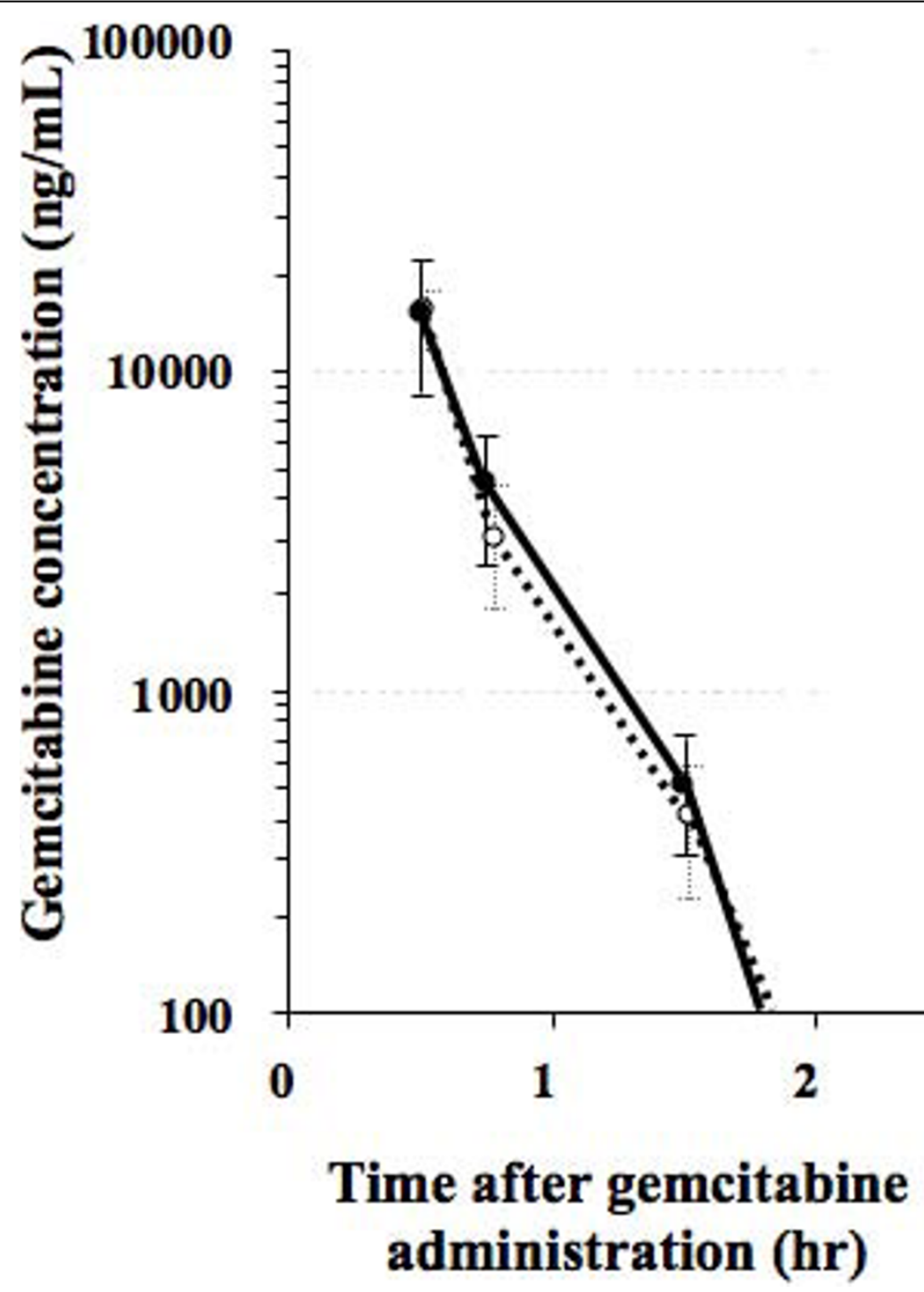

Figure 2 Plasma concentrations of gemcitabine (GEM) after administration of GEM $800 \mathrm{mg} / \mathrm{m}^{2}$ alone (open circles) and GEM $800 \mathrm{mg} /$ $\mathrm{m}^{2}+\mathrm{S}-130 \mathrm{mg} / \mathrm{m}^{2}$ (closed circles) 
Table 2 Comparison of pharmacokinetic parameters of 5-fluorouracil in plasma between administration of S-1 alone and gemcitabine (GEM)+S1

\begin{tabular}{lcccc}
\hline & $\begin{array}{c}\text { Cmax } \\
\text { (ng/ml) }\end{array}$ & $\begin{array}{c}\text { AUCinf } \\
\text { (hXng/ml) }\end{array}$ & T1/2 (h) & Tmax (h) \\
\hline Day 3 & $162 \pm 46$ & $853 \pm 329$ & $1.96 \pm 0.73$ & $3.16 \pm 0.81$ \\
(S-1 alone) & & & & \\
Day 15 & $135 \pm 56$ & $682 \pm 256$ & $2.22 \pm 0.84$ & $3.07 \pm 0.53$ \\
$\begin{array}{l}\text { (GEM+S-1) } \\
\text { P-value }\end{array}$ & 0.8644 & 0.2063 & 0.604 & 0.1683 \\
\hline
\end{tabular}

GEM was intravenously given at a dose of $800 \mathrm{mg} / \mathrm{m} 2 \mathrm{~S}-1$ was orally given at a dose of $30 \mathrm{mg} / \mathrm{m} 2$.

Cmax, maximum plasma concentration;

AUCinf, area under plasma concentration-time curve from time zero to infnite time; $\mathrm{T} 1 / 2$, elimination half-life; Tmax, the time required to reach $\mathrm{Cmax}$.

Titers were expressed as means $\pm S D(n=6)$. P-values were examined by twosided paired t-test after log-transformation.

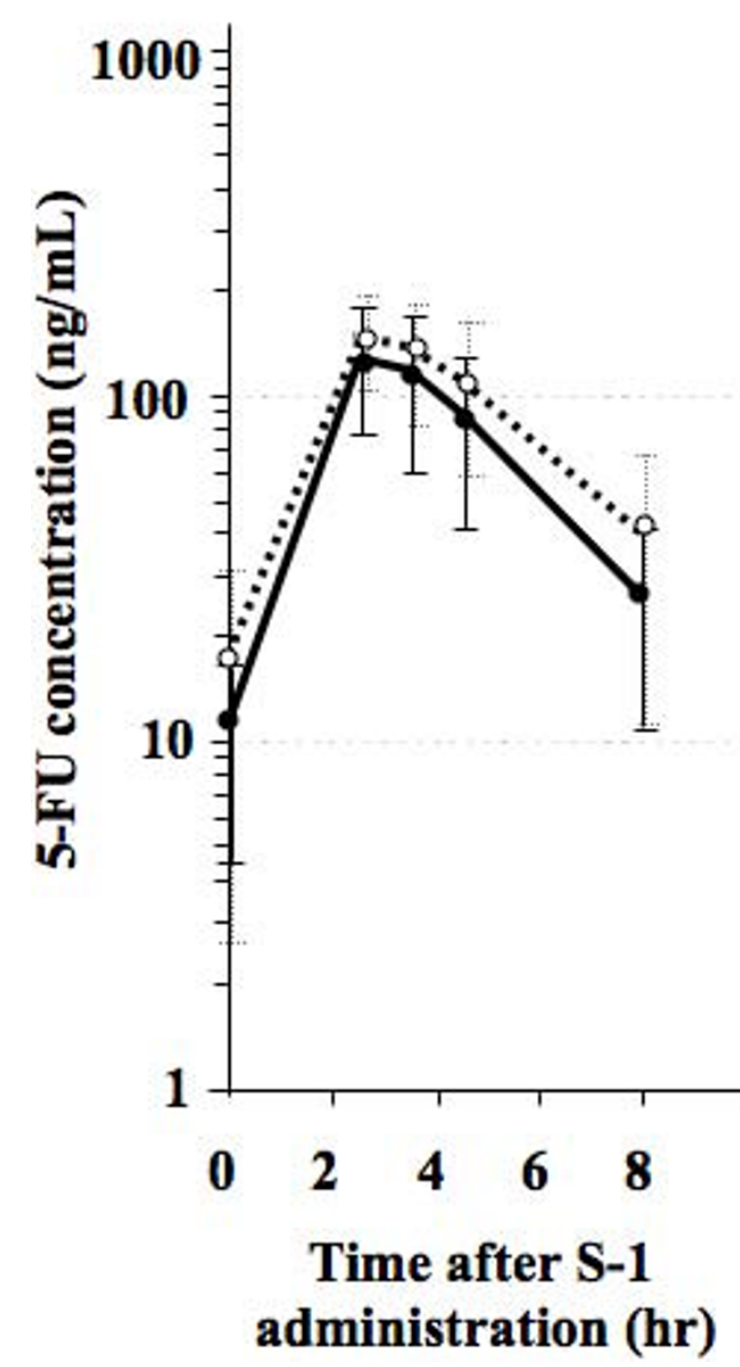

Figure 3 Plasma concentrations of 5-fluorouracil after administration of S-1 $30 \mathrm{mg} / \mathrm{m}^{2}$ alone (open circles) and GEM $800 \mathrm{mg} / \mathrm{m}^{2}+\mathrm{S}-130 \mathrm{mg} / \mathrm{m}^{2}$ (closed circles).
The sample size affects the statistical accuracy, however, the ethical matters limit the sample size. There have been some reports statistically comparing the PK parameters between two groups composed of five or six patients $[13,14]$. In our study on six patients, the statistical analysis was done to detect the relative change of the PK parameters in individual patients using the paired Student's $t$-test. In this analysis, the statistical power depends on the intra-individual variance and not on the inter-individual variance.

Correale $e t a l$. reported that pre-administration of GEM had an effect on the plasma PK of 5-FU [15]. In their study, 20 patients with metastatic gastroenteric carcinomas were treated with $30 \mathrm{~min}$ i.v. of $5-\mathrm{FU} 400 \mathrm{mg} /$ $\mathrm{m}^{2}$ and folinic acid (FA) $100 \mathrm{mg} / \mathrm{m}^{2}$ at $1 \mathrm{~h}$ after $30 \mathrm{~min}$ i. v. of GEM $1000 \mathrm{mg} / \mathrm{m}^{2}$. The control group (5-FU/FA group) consisted of 16 patients with gastroenteric carcinomas receiving $30 \mathrm{~min}$ i.v. of 5 -FU $400 \mathrm{mg} / \mathrm{m}^{2}$ and FA $100 \mathrm{mg} / \mathrm{m}^{2}$. The AUC of plasma 5-FU in GEM+5-FU/FA group was approximately twice as high as that in 5-FU/ FA group. The Cmax and T1/2 of 5-FU in GEM+5-FU/ FA group were higher than those in 5-FU/FA group. The enhanced 5-FU systemic exposure in the presence of GEM may induce severe adverse events as well as high levels of antitumor activity. In fact, a clinical phase I/II trial testing GEM+5-FU/FA for 51 patients with gastroenteric cancers reported frequent grade 4 gastroenteric toxicity and two treatment-related deaths [15].

In contrast to the study by Correale et al., in our examination, the plasma Cmax, AUCinf and T1/2 of 5FU after co-administration of S-1 with GEM showed no increases when compared to those after S-1 singleadministration (Table 2, Figure 3). Although significant differences were not shown, the mean values of Cmax and AUCinf of 5-FU at day 15 were lower than those at day 3 (Table 2). The reason is obscure, however, continuous administration of $\mathrm{S}-1$ might affect $5-\mathrm{FU}$ pharmacokinetics.

In the catabolic pathways, 5 -FU is degraded by DPD. As S-1 contains a very strong DPD inhibitor, CDHP, the Cmax and AUCinf of plasma 5-FU after S-1 administration may reach the limit expected by the amount of tegafur present in S-1. The affects of GEM metabolites on Cmax and AUC of plasma 5-FU after S-1 administration may be little lower than expected based on the presence of CDHP in plasma. The above-mentioned mechanism may explain our results that PK parameters of plasma 5FU after S-1 administration did not differ with and without GEM administration. Moreover, no enhancement of 5-FU systemic exposure after S-1 administration in the presence of GEM may be an advantage in reducing the frequency of adverse events [16].

The synergistic effects of S-1 and GEM may be explained by the following mechanism occurring in 
tumor cells. S-1 is converted into 5-FU. An active metabolite of 5-FU is fluorodeoxyuridine monophosphate (FdUMP), which inhibits DNA synthesis by forming of ternary complex with 5,10-methylene tetrahydrofolate and thymidylate synthase. GEM inhibits ribonucleotid reductase, a key enzyme in the salvage pathway of pyrimidine biosynthesis. Consequently, GEM reduces the synthesis of deoxyuridine monophosphate, a major competitor of FdUMP, resulting enhancement of 5-FU cytotoxicity [17]. Another potential mechanism is that $5-\mathrm{FU}$ leads to an increase in cell surface human equilibrative nucleoside transporter 1 (hENT1) $[18,19]$. The most active GEM uptake is via hENT1. Thus, increased hENT1 expression by 5-FU may augment GEM cytotoxicity by increasing GEM concentrations in tumor cells.

In conclusion, the present study obtained by the limited number of patients demonstrated the combination chemotherapy of S-1 with GEM did not affect the PK of each drug. As S-1 combined with GEM may be a promising regimen, further investigations should be carried out to elucidate the synergistic mechanisms between the two drugs.

\section{List of abbreviations}

GEM: gemcitabine; 5-FU: 5-fluorouracil; PK: pharmacokinetics; Cmax: maximum concentration; AUCinf: area under the curve from the drug administration to the infinite time; T1/2: elimination half-life; Tmax: time required to reach Cmax; EGFR: epidermal growth factor receptor; DPD: dihydropyrimidine dehydrogenase; CDHP: 5-chloro-2,4-dihydrogenase; MST: median survival time; PS: performance status; i.v.: intravenously; HPLC: high-performance liquid chromatography; LC/ MS: high-performance liquid chromatographic-mass spectrometry; FdUMP: fluorodeoxyuridine monophosphate; hENT1: human equilibrative nucleoside transporter 1 .

\footnotetext{
Authors' contributions

$\mathrm{BN}$ have made substantially contribution to conception, design, data analysis, interpretation of data, and drafting the manuscript. RA, SN, TT, OS, $\mathrm{TH}$, and $\mathrm{YO}$ have made substantial contributions to patients sample collection and acquisition of data. NY and $\mathrm{KH}$ have made contributions to revising the manuscript critically for important intellectual content. All authors read and approved the final manuscript.
}

\section{Competing interests}

The authors declare that they have no competing interests.

Received: 4 January 2010

Accepted: 24 February 2010 Published: 24 February 2010
References

1. Moore MJ, Goldstein D, Hamm J, Figer A, Hecht JR, Gallinger S, Au HJ, Murawa P, Walde D, Wolff RA, Campos D, Lim R, Ding K, Clark G, Voskoglou-Nomikos T, Ptasynski M, Parulekar W, National Cancer Institute of Canada Clinical Trials Group: Erlotinib plus gemcitabine compared with gemcitabine alone in patients with advanced pancreatic cancer: a phase III trial of the National Cancer Institute of Canada Clinical Trials Group. J Clin Oncol 2007, 25:1960-1966.

2. Shirasaka T, Shimamato $Y$, Ohshimo $H$, Yamaguchi M, Kato T, Yonekura K, Fukushima M: Development of a novel form of an oral 5-fluorouracil derivative (S-1) directed to the potentiation of the tumor selective cytotoxicity of 5 -fluorouracil by two biochemical modulators. Anti-Cancer Drugs 1996, 7:548-557.

3. Okusaka T, Funakoshi A, Furuse J, Boku N, Yamao K, Ohkawa S, Saito H: A late phase II study of S-1 for metastatic pancreatic cancer. Cancer Chemoth Pharm 2008, 61:615-621.

4. Nakamura K, Yamaguchi T, Ishihara T, Kobayashi A, Tadenuma H, Sudo K, Kato $\mathrm{H}$, Saisho $\mathrm{H}$ : Phase I trial of oral S-1 combined with gemcitabine in metastatic pancreatic cancer. Br J Cancer 2005, 92:2134-2139.

5. Ueno H, Okusaka T, Ikeda M, Ishiguro Y, Morizane C, Matsubara J, Furuse J, Ishii $H$, Nagase M, Nakachi K: A phase I study of combination chemotherapy with gemcitabine and oral S-1 for advanced pancreatic cancer. Oncology 2005, 69:421-427.

6. Nakamura K, Yamaguchi T, Ishihara T, Sudo K, Kato H, Saisho H: Phase II trial of oral S-1 combined with gemcitabine in metastatic pancreatic cancer. Br J Cancer 2006, 94:1575-1579.

7. Ueno H, Okusaka T, Furuse J, Yamao K, Funakoshi A, Boku N, Ohkawa S, Makimoto A, Sato T: A multicenter phase II study of gemcitabine and S-1 combination therapy (GS therapy) in patients with metastatic pancreatic cancer. J Clin Oncol 2007, 25, Abst\#4550.

8. Kim WY, Nakata B, Hirakawa K: Alternative pharmacokinetics of S-1 components, 5 -fluorouracil, dihydrofluorouracil and $\alpha$-fluoro- $\beta$-alanine after oral administration of S-1 following total gastrectomy. Cancer Sci 2007, 98:1604-1608.

9. Chun YS, Ho JJL, Kim YS, Tanaka H, Nakata B, Hiura A, Motoyoshi H, Satake $\mathrm{K}$, Umeyama $\mathrm{K}$ : The detection of human pancreatic cancerassociated antigen in the serum of cancer patients. Cancer 1987, 60:1636-1643.

10. Burris HA, Moore MJ, Andersen J, Green MR, Rothenberg ML, Modiano MR, Cripps MC, Portenoy RK, Storniolo AM, Tarassoff P, Nelson R, Dorr FA, Stephens CD, Von Hoff DD: Improvements in survival and clinical benefit with gemcitabine as first-line therapy for patients with advanced pancreas cancer: A randomized trial. J Clin Oncol 1997, 15:2403-2413.

11. Abbruzzese JL, Grunewald R, Weeks EA, Gravel D, Adams T, Nowak B, Mineishi S, Tarassoff P, Satterlee W, Raber MN: A phase I clinical, plasma, and cellular pharmacology study of gemcitabine. J Clin Oncol 1991, 9:491-498.

12. Nakamura K, Yamaguchi T, Ishihara T, Sudo K, Kobayashi A, Tadenuma H, Ishiguro $\mathrm{H}$, Saisho $\mathrm{H}$ : A phase II and pharmacokinetic trial of oral S-1 combined with gemcitabine (GEM) in patients with metastatic pancreatic cancer (MPC). J Clin Oncol 2005, 23, Abst\#4114.

13. Koizumi W, Tanabe S, Saigenji K, Ohtsu A, Boku N, Nagashima F, Shirao K, Matsumura Y, Gotoh M: Phase I/II study of S-1 combined with cisplatin in patients with advanced gastric cancer. Br J Cancer 2003, 89:2207-2212.

14. Fujitani $K$, Narahara H, Takiuchi H, Tsujinaka T, Satomi E, Gotoh M, Hirao M, Furukawa H, Taguchi T: Phase I and Pharmacokinetic Study of S-1 Combined with Weekly Paclitaxel in Patients with Advanced Gastric Cancer. Oncology 2005, 69:414-420.

15. Correale P, Cerretani D, Marsili S, Pozzessere D, Petrioli R, Messinese S, Sabatino M, Roviello F, Pinto E, Francini G, Giorgi G: Gemcitabine increases systemic 5-fluorouracil exposure in advanced cancer patients. Eur J Cancer 2003, 39:1547-1551.

16. Milano G, Etienne MC, Renee N, Thyss A, Schneider M, Ramaioli A Demard F: Relationship between fluorouracil systemic exposure and tumor response and patients survival. J Clin Oncol 1994, 12:1291-1295.

17. Madajewicz S, Hentschel P, Burns P, Caruso R, Fiore J, Fried M, Malhotra H, Ostrow S, Sugarman S, Viola M: Phase I chemotherapy study of biochemical modulation of folinic acid and fluorouracil by gemcitabine 
in patients with solid tumor malignancies. J Clin Oncol 2000, 18:3553-3557.

18. Pressacco J, Mitrovski B, Erlichman C, Hedley DW: Effects of thymidylate synthase inhibition on thymidine kinase activity and nucleoside transporter expression. Cancer Res 1995, 55:1505-1508.

19. Nakahira S, Nakamori S, Tsujje M, Takeda S, Sugimoto K, Takahashi Y, Okami J, Marubashi S, Miyamoto A, Takeda Y, Nagano H, Dono K, Umeshita K, Sakon M, Monden M: Pretreatment with S-1, an oral derivative of 5-fluorouracil, enhances gemcitabine effects in pancreatic cancer xenografts. Anticancer Res 2008, 28:179-186.

doi:10.1186/1756-9966-29-15

Cite this article as: Nakata et al.: Plasma pharmacokinetics after combined therapy of gemcitabine and oral S-1 for unresectable pancreatic cancer. Journal of Experimental \& Clinical Cancer Research 2010 29:15.

Submit your next manuscript to BioMed Central and take full advantage of:

- Convenient online submission

- Thorough peer review

- No space constraints or color figure charges

- Immediate publication on acceptance

- Inclusion in PubMed, CAS, Scopus and Google Scholar

- Research which is freely available for redistribution

Submit your manuscript at www.biomedcentral.com/submit 